\title{
Tensile behaviour of high temperature forged Ti-6Al-4V during in-situ heat treatments
}

\author{
R. Julien ${ }^{\mathrm{a}}$, V. Velay ${ }^{\mathrm{a}}, \mathrm{V}$. Vidal ${ }^{\mathrm{a}}$, Y. Dahan ${ }^{\mathrm{b}}$, R. Forestier ${ }^{\mathrm{b}}$, F. Rézaï-Aria ${ }^{\mathrm{a}, *}$ \\ ${ }^{a}$ Université de Toulouse; CNRS, Mines Albi, INSA, UPS, ISAE-SUPAERO ; ICA (Institut Clément Ader); \\ Campus Jarlard, F-81013 Albi, France \\ ${ }^{b}$ Aubert et Duval Pamiers; 75 Boulevard de la Libération, BP 173, 09102 Pamiers Cedex, France
}

\begin{abstract}
Tensile behaviour of the $\alpha+\beta$ Ti-6Al-4V titanium alloy is investigated while quenching. A new insitu thermal and mechanical treatments facility is developed. Different time-temperature and timemechanical strain histories are coupled to investigate the uniaxial tensile properties and strength of this alloy during quenching. The microstructural evolutions are reported and their influences on the mechanical behaviour are addressed.
\end{abstract}

Keywords: Titanium alloy, Heat treatments, Mechanical behaviour, Microstructural evolution, Residual stress

\section{Introduction}

In general, following a high temperature mechanical processing (for example hot forging), materials are thermally heat-treated and quenched. While quenching, phase transformations and microstructural evolutions, such as the secondary phases morphology changes may occur. In ad-

5 dition, depending on the shape and the dimension of parts, as well as the nature of quenching environments (Air, Oil, etc.), different transient thermal gradients can be generated in parts. Subsequently, different transient local thermal "expansion/contraction" histories can be generated. Due to thermal self-constraining, different internal mechanical strains and stresses (so-called residual stresses) are generated. These internal stresses vary from one region to another in a part, in particular in large dimension components. During subsequent machining steps, the internal strains/stresses are released causing the distortion of parts. In addition, highly localised residual strains/stresses are generated on the subsurface layer of the machined parts. All these residual strains/stresses can drastically modify the mechanical behaviour and damage the development of the industrial components in service. The modelling of the internal strains and stresses are there-

15 fore needed $[1,2,3]$ for a better thermomechanical processing of materials and in particular in advanced processing such as Additive Manufacturing [4].

\footnotetext{
${ }^{*}$ Corresponding author

Email address: rezai@mines-albi.fr (F. Rézaï-Aria)
} 
Ti-6Al-4V alloy is a widely used in aeronautical applications [5]. Depending on the microstructure needs $(\alpha+\beta$ or $\beta)$, heat-treatments can be performed under or above $\beta$-transus temperature $[6,7]$. This contribution deals with an investigation on the mechanical behaviour of this alloy by 20 in-situ heat treatments and tensile experiments carried out at various temperatures (ranging from $950^{\circ} \mathrm{C}$ to Room Temperature RT) and a cooling rate of $60^{\circ} \mathrm{C} / \mathrm{min}$. The fraction of both $\alpha$ and $\beta$ phases are evaluated by image analysis [3]. Test conditions assessed consist in temperature increase up to $950^{\circ} \mathrm{C}$ followed by a dwell time of 2 hours at this temperature corresponding to closed-die forging stage. Then temperature decrease is carefully controlled and monitored to simulate the quenching stage of forging. These conditions are representative of possible industrial heat treatments. It is shown that the mechanical behaviour can be explained by microstructural evolutions of $\beta$-phase at higher temperatures and by $\alpha$-phase morphology changes at lower temperatures.

\section{Experiments and material}

Wrought bars are first cut from a billet by abrasive water jet cutting and then cylindrical so specimens are machined by turning. Bars were cut parallel to the main macroscopic forging loading axis to minimize the microstructural texture effects. The initial microstructure consists of the equiaxe $\alpha$-nodules embedded in $\beta$-phase.

A new high temperature experimental facility using conventional hydraulic pull/pushed testing machine and induction heating is developed. The specimens are heated by a $2 \mathrm{~kW}$ Celes generator.

35 A dummy cylindrical specimen was first instrumented by several spots welded thermocouples to control the longitudinal and circumferential temperature gradients. In the gauge length thermal gradients were about $1^{\circ} \mathrm{C} / \mathrm{mm}$ and $1^{\circ} \mathrm{C} / 120^{\circ}$ angle respectively in longitudinal and circumferential directions. The strain is measured in gauge length by high temperature extensometer having ceramic rods.

40 The time-temperature history is monitored via a spot-welded K-thermocouple on the specimen gauge length (Figure 1 (a)). Following a heat-treatment of the specimen by maintain constant the temperature around $950^{\circ} \mathrm{C}(\alpha+\beta$ domain) for about 2 hours, the specimen is then cooled down by pressurized air (about 5 bars) to achieve a prescribed temperature. Then, after only few seconds dwell time, the tensile tests are performed in air atmosphere by maintaining the temperature constant during tensile test. A boron nitride protection layer was deposited on the surface of specimens in order to limit the oxidation. The strain-time cycle consisted of tensile loading at strain rates of $10^{-4}, 10^{-3}$ or $10^{-2} \mathrm{~s}^{-1}$, first up to $1 \%$ total strain; then 10 minutes dwell time under constant total strain; following tensile re-loading up to an additional $1 \%$ total strain. After this $2 \%$ cumulative total strain, the specimen is cooled down to RT by air (naturally or pressurised) under nil stress. Various temperatures and strain rates are examined (Figure 1 (a)). 


\section{Results and discussions}

The mechanical properties in particular at high temperature are generally governed the microstructure and phase transformations [8]. Post-mortem optical and SEM observations at RT associated with image analysis have revealed microstructural evolutions in terms of the fraction, size and morphologies of $\alpha$ and $\beta$ phases. In particular, during cooling at $60^{\circ} \mathrm{C} / \mathrm{min}$ from $950^{\circ} \mathrm{C}$ to $800^{\circ} \mathrm{C}$, there is no significant evolutions of the nodules of $\alpha_{I}$ while $\beta$-matrix transforms into $\beta+\alpha_{I I}$ lamellar structure. The phase transformation is already completed at temperatures below than $800^{\circ} \mathrm{C}$ (Figure 2).

Figure 1 (b) shows the tensile curves for all testing temperatures. A Portevin-Le Chatelier (PLC) phenomenon is observed at intermediate temperatures from $600^{\circ} \mathrm{C}$ to $300^{\circ} \mathrm{C}$. PLC can occurred, depending on temperature of tensile test, strain rate and also quenching rate. It is supposed that when the quenching rate decreases, the strain level required to provoke the PLC phenomenon is increased since the $\alpha_{I I}$ lamellae thickness increases [3].

Three major temperature ranges are identified with different non-linear plastic strain yielding, strain hardening and viscous behaviour. First, from $950^{\circ} \mathrm{C}$ to $600^{\circ} \mathrm{C}$, the tensile strength decreased with reducing the strain rate showing a higher contribution of time dependent phenomenon (Figure 3 (a)). During 10 min dwell time, stress relaxation is observed. At the end of dwell time, the non-viscous part of stress, so called internal stress $\left(\sigma_{i}\right)$, was identified. $\sigma_{i}$ value is quasi-nil between $950^{\circ} \mathrm{C}$ to $800^{\circ} \mathrm{C}$ (Figure 1 (b)). Therefore, one can consider that, the hardening is "fully recovered" due to the available thermal energies. A relative stress relaxation range (effective stress), $\left(\sigma_{1 \%}-\sigma_{i}\right) / \sigma_{i}$, is defined and reported as a function of $1 /(\mathrm{R} \theta)$ with $\mathrm{R}$ as the gas constant (8.31 J.mol ${ }^{-1} \cdot \mathrm{K}^{-1}$ ) (Figure $3(\mathrm{~b})$ ). As can be noted, the tensile stress relaxation investigated here and the cyclic stress relaxation reported by Longuet et al. [1] under a 1 min dwell time testing present the same trend, independently to their different heat treatments and microstructure states. As the process of stress relaxation in Longuet et al. study is not fully completed after 1 min hold time, $\sigma_{i}$ values obtained from our tensile relaxation investigations are used. In addition, tensile curves at $900^{\circ} \mathrm{C}$ and in particular at $950^{\circ} \mathrm{C}$ show a pronounced tensile yield point phenomenon [9]. This is followed by a stress softening with the increasing of the total strain. It is assumed that the post yield point softening and the tensile stress relaxation are governed by the same activated diffusional

80 processes. The relative stress softening, defined as $\left(\sigma_{1 \%}-\sigma_{i}\right) / \sigma_{i}$, is also reported in Figure 3 (b). As illustrated, an Arrhenius's type law, with an activation energy of about $72.7 \mathrm{~kJ} / \mathrm{mol}$, describes the time dependent part of the tensile strength of Ti-6Al-4V alloy. This diffusion energy could be related to rearrangement of dislocations [10] or microstructural evolutions [11].

Secondly, from $600^{\circ} \mathrm{C}$ to $400^{\circ} \mathrm{C}$, the plastic strain hardening was still dominant (Figure 1 (b)) and a significant strain rate dependence was revealed (Figure 3 (a)). However, Figure 3 (b) illustrates an important tensile stress relaxation during dwell time. 
Lastly, from $400^{\circ} \mathrm{C}$ to $\mathrm{RT}$, the plastic strain yielding and hardening mostly govern the tensile behaviour as shown in Figure 1 (b). The tensile behaviour in this range of temperature is not drastically strain rate dependant (Figure $3(\mathrm{a})$ ). For these conditions, the tensile stress relaxation

90 is temperature independent (Figure 3 (b)). However, a small stress relaxation may still be observed (Figure $1(b)$ ).

\section{Summary}

A new experimental facility is developed to investigate the in-situ heat treatments effects on quasi-static tensile behaviour and resistance of Ti-6Al-4V alloy. The effect of strain rate and temperature is evaluated from $950^{\circ} \mathrm{C}$ to $\mathrm{RT}$ for strain rates ranging between $10^{-4} \mathrm{~s}^{-1}$ to $10^{-2} \mathrm{~s}^{-1}$. It is observed that the $\alpha+\beta$ microstructures evolve during quenching rate of $60^{\circ} \mathrm{C} / \mathrm{min}$ and dwell tensile testing. An activation energy of about $72.7 \mathrm{~kJ} / \mathrm{mol}$ is found to govern the time dependent microstructural evolutions. The PLC is observed but not addressed in the present contribution. Based on these observations, a thermomechanical model is formulated to assess the residual stresses generated during cooling in industrial parts [3].

\section{Acknowledgments}

The authors very much acknowledge the financial support from FUI grant in the frame of the collaborative project TiMaS (Titanium Machining and Simulation) leaded by Airbus. The authors also gratefully acknowledge Figeac Aéro for the machining of samples.

\section{References}

[1] A. Longuet, Y. Robert, E. Aeby-Gautier, B. Appolaire, J. Mariage, C. Colin, G. Cailletaud, Computational Materials Science 46 (3) (2009) 761-766.

[2] J. Teixeira, B. Denand, E. Aeby-Gautier, S. Denis, Materials Science and Engineering A 651 (2016) 615-625.

${ }_{110}$ [3] R. Julien, Ph.D. thesis, École des Mines d'Albi (2017/02/20).

[4] F. Rézaï-Aria, R. Lacoste, M. Salem, T. Pottier, J. Bajolet, in: 10th International TOOL Conference, 2016, p. 5.

[5] D. Banerjee, J. Williams, Acta Materialia 61 (3) (2013) 844-879.

[6] G. Lütjering, Materials Science and Engineering: A 243 (1998) 32-45.

[7] C. Sauer, G. Luetjering, Journal of Materials Processing Technology 117 (3) (2001) 311-317.

[8] S. Roy, S. Suwas, Journal of Alloys and Compounds 548 (2013) 110-125. 
[9] S. Abbasi, A. Momeni, A. Akhondzadeh, S. Ghazi Mirsaed, Materials Science \& Engineering A 639 (2015) 21-28.

[10] H. Jousset, Ph.D. thesis, École des Mines de Paris (2008).

120 [11] R. Dąbrowski, Archives of Metallurgy and Materials 56 (2) (2011) 217-221. 


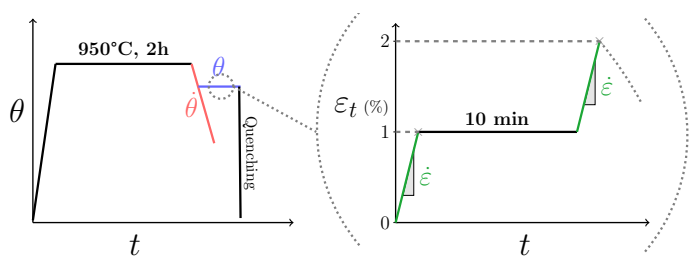

(a)

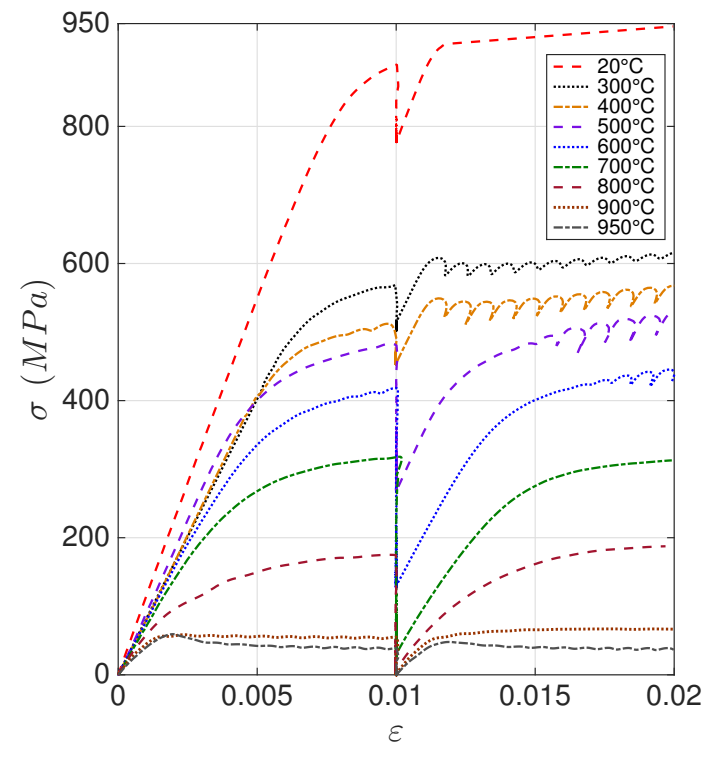

(b)

FIG. 1: (a) Schematic typical thermo-mechanical treatments; (b) Mechanical responses $\sigma-\varepsilon$ at several temperatures

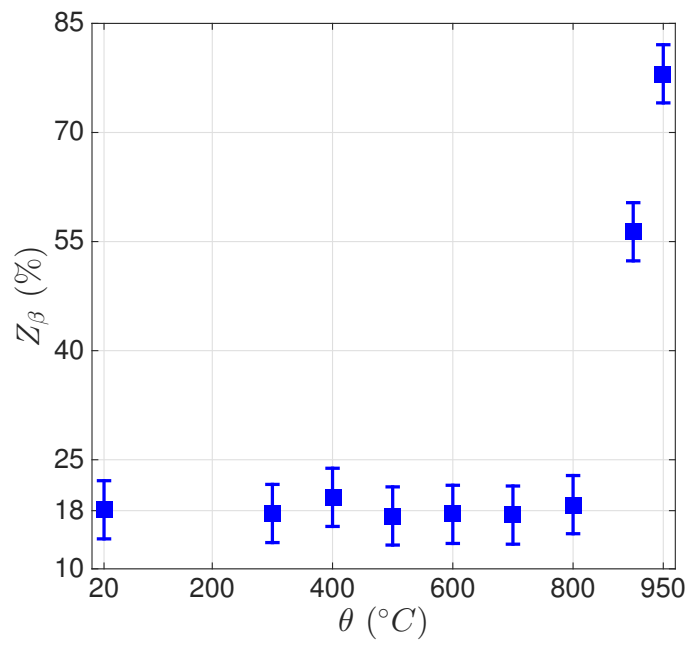

FIG. 2: Evolution of $\beta$ phase fraction as a function of temperature of tensile testing after a cooling rate of $60^{\circ} \mathrm{C} / \mathrm{min}$ 


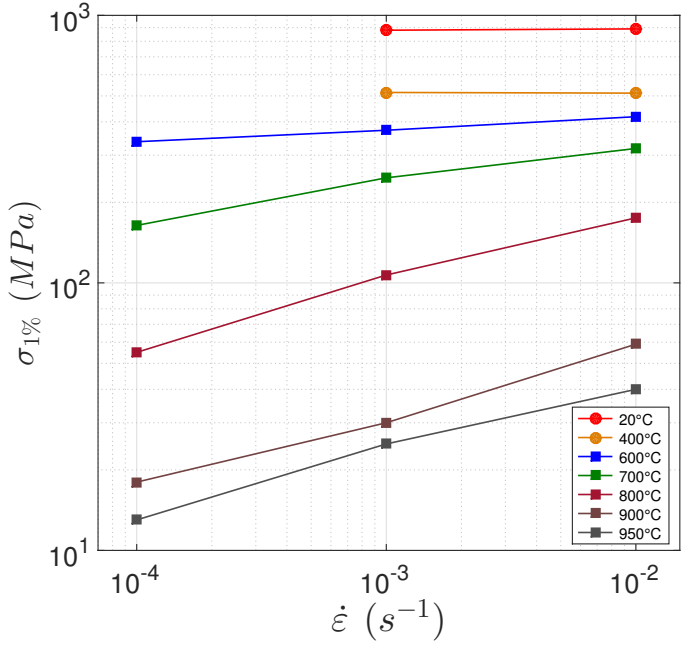

(a)

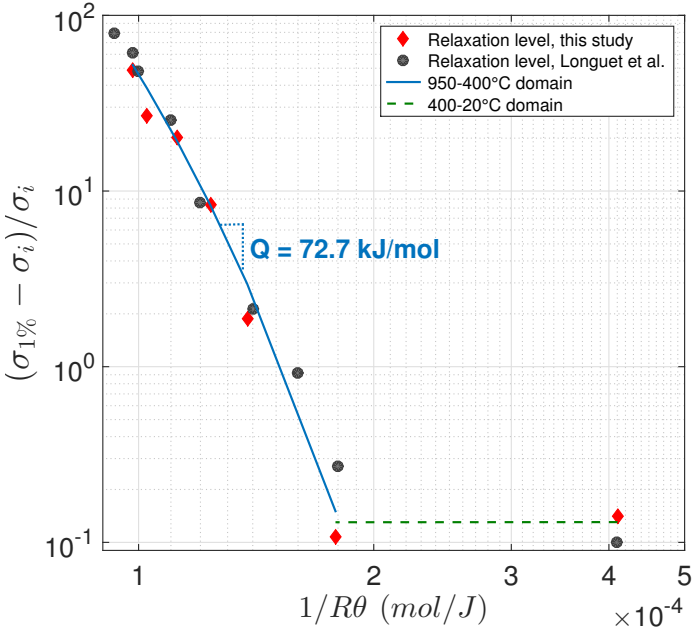

(b)

FIG. 3: (a) Stress at 1\% of total deformation versus strain rate; (b) Stress relaxation evolution during cooling 